\title{
Perfil da Assistência Farmacêutica no Município de Tremedal - BA
}

\author{
Anita da Silva Pinto ${ }^{1}$; Matheus Santos Marques ${ }^{2}$
}

\begin{abstract}
Resumo: Assistência Farmacêutica é o conjunto de ações que visam a promoção, proteção e recuperação da saúde e contribução na qualidade de vida da população. Este estudo teve como objetivo geral: avaliar como é realizada a assistência farmacêutica no município de Tremedal - BA. Trata-se de uma pesquisa de natureza quantitativa, com objetivos de cunho descritivo acompanhada do procedimento técnico de pesquisa de campo. Foram entrevistados 03 farmacêuticos da rede privada e um da rede pública, em que foi aplicado um questionário contendo 15 questões que abordaram o tema em questão.Embora tenha se constatado que $100 \%$ dos entrevistados estão de acordo com o que rege a RDC $\mathrm{N}^{\circ} 44$,no tocante a três aspectos, compreende-se que o município investigado é carente de Assistência Farmacêutica, a começar pelo número de farmacêuticos na rede pública, que é inferior ao que se recomenda, e que não promovem a devida assistência aos pacientes, como era de se esperar. Enquanto que na rede privada, o objetivo maior é realizar as vendas do medicamento e não prestar a devida atenção farmacêutica. Espera-se com este trabalho suscitar reflexões sobre a importância da Assistência Farmacêutica para aqualidade de vida da população seja melhorada.
\end{abstract}

Palavras-Chave: Assistência Farmacêutica. Rede Pública. Rede Privada.

\section{Profile of Pharmaceutical Assistance in the Municipality of Tremedal - BA}

Abstract: Pharmaceutical Assistance is the set of actions that aim at the promotion, protection and recovery of health and contribution in the quality of life of the population. The objective of this study was to evaluate how pharmaceutical care is performed in the municipality of Tremedal - BA. This is a quantitative research, with descriptive objectives accompanied by the field research technical procedure. We interviewed 03 pharmacists from the private network and one from the public network, in which a questionnaire was applied containing 15 questions that approached the subject in question. Although it was verified that $100 \%$ of the interviewed ones are in agreement with the one that governs the RDC $\mathrm{N}^{\circ} 44$, with regard to three aspects, it is understood that the investigated municipality is lacking in Pharmaceutical Care, starting with the number of pharmacists in public, which is lower than what is recommended, and do not promote proper patient care, as was Be expected. While in the private network, the main goal is to realize the sales of the drug and not to give the due pharmaceutical attention. It is hoped that this work will stimulate reflections on the importance of Pharmaceutical Care to improve the quality of life of the population.

Keywords: Pharmaceutical Assistance. Public network. Private Network.

\footnotetext{
${ }^{1}$ Graduanda em farmácia pela Faculdade Independente do Nordeste - FAINOR. E-mail: binhalindinha40@ gmail.com;

${ }^{2}$ Graduação em Farmácia Bioquímica pela Universidade Federal da Bahia e especialização em Saúde Pública com complementação em Magistério Superior. Atualmente é professor contratado da Faculdade de Tecnologia e Ciências de Vitória da Conquista. Professor e coordenador do curso de Farmácia da Faculdade Maurício de Nassau (antiga Faculdade Juvêncio Terra) em Vitória da Conquista. Professor de farmacologia da pós graduação de Farmácia Clínica e Atenção Farmacêutica da UNIGRAD. Professor de Farmacologia I e Farmacologia II do curso de Farmácia da Faculdade Independente do Nordeste (FAINOR).
} 
Id on Line Revista Multidisciplinar e de Psicologia

Id on Line Multidisciplinary and Psycology Journal

\section{Introdução}

No Brasil, o serviço público de saúde é conhecido como Sistema Único de Saúde (SUS), é apontado como uma grande conquista da sociedade, tendo em vista o seu caráter de política estatal que promoveu ampla inclusão social. O SUS foi criado pela Constituição Federal - CF de 1988 e institucionalizado pela Lei Orgânica da Saúde - LOS é reconhecido em decorrência de seus princípios de universalidade e igualdade no atendimento e de integralidade das ações e serviços de saúde (VIEIRA, 2010).

Para que o serviço de saúde funcionasse em plena harmonia foi necessário a implantação do Sistema Único de Saúde - SUS por meio das Leis Orgânicas da Saúde (LOS) para que estas contribuíssem, regulamentando o sistema de saúde, sendo que essa lei foi dividida entre a Lei 8.080 e a Lei 8.142. As Leis $n^{\circ}$ 8.080/90 conhecida como Lei Orgânica da Saúde e a $n^{\circ}$ 8.142/90, regulamentaram o SUS após sua criação, estas leis definiram as atribuições de cada nível de governamental, estabeleceram responsabilidade nas áreas de vigilância epidemiológica, sanitária e saúde do trabalhador, como também regularizaram financiamento e os espaços da participação popular, dentre outros vários princípios essenciais do SUS (BRASIL, 2001).

A Assistência Farmacêutica representa uma das áreas de maior impacto financeiro no SUS de forma geral, o que também é a realidade das secretarias municipais de saúde. Ao considerar os fundamentos para que a Assistência Farmacêutica seja resolutiva, deve-se destacar que a mesma deve estar fundamentada no acesso, na qualidade, na correta prescrição e dispensação e na promoção do uso racional de medicamentos, esses fundamentos apresentamse como básicos para a resolutividade da Assistência Farmacêutica e do SUS (BRASIL, 2010b).

Uma das prioridades da Política Nacional de Medicamentos (PNM), reafirmada pela Política Nacional de Assistência Farmacêutica (PNAF), é a revisão permanente da Relação Nacional de Medicamentos Essenciais (RENAME) com base nas prioridades nacionais de saúde, considerando segurança, eficácia terapêutica comprovada, qualidade e disponibilidade de produtos farmacêuticos (BRASIL, 2004).

Medicamentos essenciais se constituem em um dos principais instrumentos para a realização de uma efetiva política de medicamentos, e são definidos pela Organização Mundial da Saúde (OMS) como:“...aqueles que servem para satisfazer às necessidades de atenção à 
Id on Line Revista Multidisciplinar e de Psicoloqia

Id on Line Multidisciplinary and Psycology Journal

saúde da maioria da população. São selecionados de acordo com a sua relevância na saúde pública, provas quanto à eficácia e à segurança e com estudos comparados de custo-efetividade. Devem estar sempre disponíveis, nas quantidades adequadas, nas formas farmacêuticas requeridas e a preços que os indivíduos e a comunidade possam pagar...”. O país elaborou a sua primeira lista de medicamentos essenciais em 1964, 13 anos antes da recomendação inicial feita pela OMS, em 1977. Assim, o Brasil há muito tempo vem pautando suas políticas de medicamentos segundo critérios internacionalmente aceitos (BRASIL, 2010b).

De acordo com o supracitado surge a pergunta norteadora: de que forma ocorre a assistência farmacêutica no município de Tremedal - Bahia? Por isso, este estudo apresenta como objetivo geral: avaliar como é realizada a assistência farmacêutica no município de Tremedal - BA. E objetivos específicos: verificar quantas farmácias são do serviço privado e quantas são do serviço público; conhecer as bases legais para o funcionamento das mesmas; analisar de que forma uma assistência ineficiente pode prejudicar a população; e identificar quantos farmacêuticos existem no local e como estão distribuídos.

Este estudo é relevante para os profissionais farmacêuticos, pois contém dados que possibilitará avaliar como é realizado todo o processo de assistência farmacêutica, tanto de cunho particular como público a fim de suscitar discussões e melhorias nos serviços de assistência farmacêutica no município Tremedal - BA e farmácias e drogarias de outras regiões.

\section{Metodologia}

Trata-se de uma pesquisa de natureza quantitativa, visto que a pesquisa dessa natureza traduz tudo que pode ser quantificável conforme afirma Mattar (2001). No que se refere aos objetivos apresenta característica descritiva, pois se trata de um estudo fundamentado que visa descrever dados próprios de uma determinada população ou fenômeno, sempre procurando estabelecer relações entre si. Também apresenta característica exploratória, pois procura esclarecer fatos de determinado tema com o intuito de modificar ideias que possam solucionar determinada premissa. Gil (2008) explica ainda que esse tipo de pesquisa tenta familiarizar os envolvidos no problema tornando-o mais explícito para a solução de novas hipóteses. 
Id on Line Revista Multidisciplinar e de Psicologia

Id on Line Multidisciplinary and Psycology Journal

Quanto aos procedimentos técnicos é caracterizado como pesquisa de campo, pois de acordo com Gil (2008) esse tipo de pesquisa está voltado para a interrogação direta das pessoas diante dos fatos e comportamentos que se deseja conhecer. Ainda segundo o autor este procedimento técnico tem como vantagem a elaboração da mesma a partir de material já publicado, constituído principalmente de livros, artigos de periódicos e atualmente com material disponibilizado na internet.

A pesquisa foi realizada no município de Tremedal - Bahia, local este que possui 03 (três) centrais de medicações de cunho privado e 01 (uma) da rede pública. Tremedal é um município brasileiro do estado da Bahia, distante cerca de 590 quilômetros da capital. Sua população em 2010 era de 17.029 habitantes, segundo os dados do IBGE. A localidade passou a ser conhecida como Tremedal dos Ferraz, devido ao espírito empreendedor da Família Ferraz, sendo uma das primeiras famílias a se estabelecer na localidade.

Os participantes que compuseram a totalidade dos entrevistados foram 03 (três) farmacêuticos da rede privada e 01 (um) farmacêutico da rede pública. A pesquisa não se deu com número maior de entrevistados, porque aquantidade de farmácias dentro do município em questão é escassa. $\mathrm{O}$ instrumento de coleta dos dados foi o questionário estruturado que conteve 15 questões (APÊNDICE A) elaboradas pelo autor desta pesquisa. Os participantes da pesquisa foram devidamente esclarecidos e orientados quanto aos objetivos do trabalho e ficaram livres para participar, mediante assinatura do Termo de Consentimento Livre e Esclarecido - TCLE, obedecendo os princípios éticos que constam na resolução 466/12 do Conselho Nacional de Saúde - CNS, que define as diretrizes e normas regulamentadoras de pesquisas envolvendo seres.

Quanto a análise dos dados, esta foi realizada por meio dos softwares do Microsoft Word e Excel 2010, onde os dados foram tabulados e apresentados em formato de gráficos à luz do referencial teórico.

\section{Resultados e Discussão}

Entende-se por assistência farmacêutica como sendo um conjunto de ações relacionadas à dispensação de medicamentos, e tem por objetivos contribuir para o sucesso da terapêutica. É 
Id on Line Revista Multidisciplinar e de Psicologia

Id on Line Multidisciplinary and Psycology Journal

através dela que o farmacêutico passa a ser responsável pela qualidade de vida no qual o paciente encontra-se inserido. O farmacêutico nada mais é do que o profissional que garante a qualidade do medicamento, e sem o mesmo o programa de assistência farmacêutica seria um fracasso. Vale ainda salientar que os medicamentos são importantes para a melhora da condição de vida do paciente e por isso cabe ao farmacêutico orientar sobre a forma correta de consumilo (BASILE, 2008).

A pesquisa em questão contou com a participação de 4 farmacêuticos, $75 \%$ da rede privada e $25 \%$ da rede pública. E apenas $25 \%$ destes residem no município e $75 \%$ são profissionais que se deslocam de cidades circunvizinhas.

Vários tipos de serviços farmacêuticos, executados no âmbito da atenção à saúde, são avaliados positivamente na melhora da qualidade do processo de uso de medicamentos (PROFAR, 2014). Dentre os possíveis serviços prestados pelos farmacêuticos do município de Tremedal-BA, vimos que $100 \%$ dos participantes realizam a dispensação de medicamentos controlados, e 75\% deles realizam o recebimento, armazenamento e dispensação de medicamentos; seguidos de $50 \%$ que realiza a aquisição de medicamentos da farmácia e $25 \%$ que realiza, também, a aferição da pressão arterial dos clientes (GRÁFICO 1).

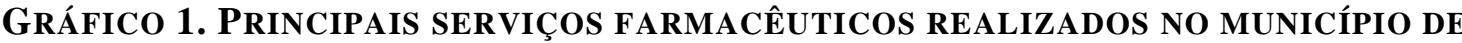 TREMEDAL-BA.}

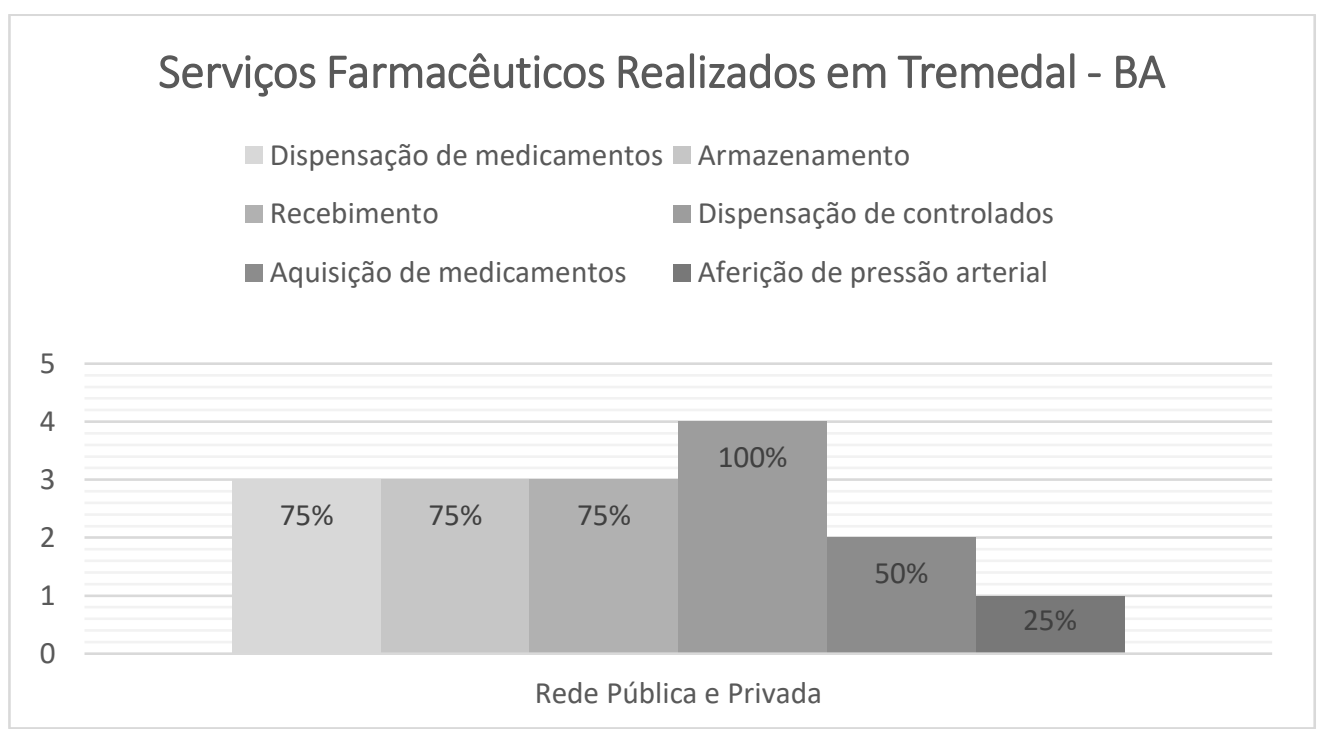

Fonte: Dados da pesquisa, Tremedal-BA, 2016. 
Id on Line Revista Multidisciplinar e de Psicologia

Id on Line Multidisciplinary and Psycology Journal

O ciclo da Assistência Farmacêutica é composto pelas etapas de seleção, programação, aquisição, armazenamento, distribuição e dispensação e deve ocorrer de maneira ordenada. A execução inadequada de algum dos itens do ciclo prejudica todos os seus outros passos, comprometendo os resultados, tendo como consequência a insatisfação do usuário, evidenciando a má gestão da Assistência Farmacêutica. A Assistência Farmacêutica apresenta componentes com aspectos de natureza técnica, científica e operativa, integrando-os de acordo com a complexidade do serviço, necessidades e finalidades (ROSEFIELD, 2008).

A atenção farmacêutica prestada, em farmácias e drogarias, contém importantes serviços que objetivam manter a qualidade de vida dos cidadãos. A fim de firmar parâmetros para estes serviços, o Conselho Federal de Farmácia publicou, em dezembro de 2008, a Resolução no 499, alterada pela Resolução n ${ }^{0}$ 505/09, que dispõe sobre a prestação de serviços farmacêuticos nestes estabelecimentos.Consoante o texto da Resolução, são serviços farmacêuticos: elaborar o perfil farmacoterapêutico; verificar a pressão arterial; determinar a quantitativa do teor sanguíneo de glicose, colesterol total e triglicérides, mediante coleta de amostras de sangue por punção capilar; executar a execução de procedimentos de inalação e nebulização; realizar curativos de pequeno porte; colocar brincos; participar de campanhas de saúde e prestar assistência farmacêutica domiciliar.

Neste sentido, constatou-se que atividades desempenhadas por estes profissionais estão em conformidade com o estabelecido no Ciclo de Assistência Farmacêutica e as resoluções firmadas pelo CFF.

Ao investigar sobre a forma como é realizada a dispensação das medicações, $75 \%$ dos entrevistados afirmaram "repasso as medicações controladas somente com as receitas e as demais, se não forem de uso controlado, vendo conforme a solicitação" e apenas $25 \%$ disse "É realizada mediante prescrição médica em casos de internamento e conforme o uso no prontoatendimento, usamos um caderno de saída para ter maior controle de estoque". Vale ressaltar que o primeiro grupo integra a rede privada e o segundo, integra a rede pública.

No marco da Política Nacional de Medicamentos foi definido pelo Consenso Brasileiro de Atenção Farmacêutica que

atenção farmacêutica é modelo de prática farmacêutica, desenvolvida no contexto da assistência farmacêutica. Compreende atitudes, valores éticos, comportamentos, habilidades, compromissos e co-responsabilidades na prevenção de doenças, promoção e recuperação da saúde, de forma integrada à equipe de saúde. É a interação 
direta do farmacêutico com o usuário, visando uma farmacoterapia racional e a obtenção de resultados definidos e mensuráveis voltados para a melhoria da qualidade de vida. Esta interação também deve envolver as concepções dos seus sujeitos, respeitadas as suas especificidades bio-psico-sociais sob a ótica da integralidade das ações de saúde (OPAS 2002).

A atenção farmacêutica coopera para o uso racional de medicamentos, pois ela visa desenvolver um acompanhamento metódico da terapia medicamentosa utilizada pelo cliente buscando ponderar e garantir a necessidade, a segurança e a efetividade no processo de utilização de medicamentos. Através das respostas dos entrevistados inferimos que nestes estabelecimentos o modo com a dispensação de medicamentos controlados ocorre coopera para o uso racional dos medicamentos, visto que os farmacêuticos só o fazem por meio de receitas e prescrições médicas. No entanto, quando se trata de outros medicamentos, $75 \%$ deles afirmam que vendem conforme solicitação. Espera-se, destes profissionais, que eles interajam com o usuário a fim de compreender se o uso do medicamento ocorrerá com segurança e se favorecerá a necessidade do paciente, garantindo a qualidade de vida do mesmo. Na medida que o farmacêutico interatua junto ao usuário, ele poderá intervir realizando, quando necessários, outros serviços tais como: verificação da pressão arterial; determinação a quantitativa do teor sanguíneo de glicose, colesterol total e triglicérides, execução de procedimentos de inalação e nebulização, por exemplo, invés de simplesmente realizar a dispensa da medicação, garantindo, assim, uma atenção farmacêutica de qualidade.

No tocante a informatização, $75 \%$ dos entrevistados, ao serem questionados sobre a forma como é a realizada a aquisição das medicações, responderam ser mediante sistema, enquanto somente $25 \%$ utiliza o bloco de faltas. Vale ressaltar que o profissional que utiliza o bloco de nota, não pertence a rede pública, mas ao contrário a rede privada. Com isso, ressaltase a importância de ferramentas como ainformática, no gerenciamento da Farmácia, principalmente na tomada de decisões.

Pinheiro (2005) sugere que os estabelecimentos comerciais farmacêuticos adotem um sistema informatizado de controle de estoque, desenvolvam um programa (software) específico que contemple as diretrizes de cadastramento informatizado dos itenscomponentes do estoque. A implantação da proposta de um sistema informatizado decontrole de estoque possibilita aos gerenciadores a aquisição rápida e precisa de relatórios com informações confiáveis e indispensáveis à tomada dedecisão para que, também, não falte determinados medicamentos ao usuário. 
Quando questiona-se aos mesmos entrevistados "Para se efetuar as compras das medicações é necessário dar entrada ao processo de licitação?", 75\% deles responde que "não", são estes profissionais da rede privada, e apenas 25\% diz que "sim", trabalhador da rede pública.

A diferença do percentual entre a rede privada e pública ocorre, porque para a compra de medicamentos no SUS é necessário que haja a programaçãocom base na relação consensual de medicamentos na fase de seleção com intuito de evitar a descontinuidade do abastecimento. As compras devem ser feitas por licitação,

\footnotetext{
É uma determinação constitucional estabelecida no art. 37, inciso XXI (BRASIL, 1988), regulamentada pela Lei Federal no 8.666, de 21 de junho de 1993, atualizada pelas Leis nos 8.883 , de 8 de junho de 1994 e 10.520/2002, que impõe à Administração Pública o dever de licitar. A licitação é um conjunto de procedimentos formais, uma série ordenada de atos, que devem ser registrados em processo próprio e obedecer aos princípios da legalidade, igualdade, publicidade, probidade administrativa, vinculação ao edital e do julgamento objetivo, entre outros (BRASIL, 2006, p. 17).
}

A forma pela qual se conduz o procedimento licitatório, é a modalidade de licitação definida pelos critérios estabelecidos pela Lei n o 8.666/1993.Uma modalidade de licitação diferencia-se de outra pelo valor da compra. A lei supracitada e a Lei n. 10.520/2002 preveem seis modalidades de licitação para compra de bens e serviços: pregão, convite, tomada de preços, concorrência, concurso e leilão.

Constatou-se com esta pesquisa que $100 \%$ dos entrevistados estão de acordo com o que rege a Resolução-RDC $\mathrm{N}^{\circ}$ 44, de 17 de Agosto de 2009, no tocante a três aspectos: "Realiza auto inspeção conforme modelo da ANVISA?", "Realiza treinamento" e "Elabora POP e Manual de Boas Práticas”, conforme verifica-se no Gráfico 2. 


\section{GRÁFICO 2.ASPECTOS EM CONFORMIDADE COM A RDC.}

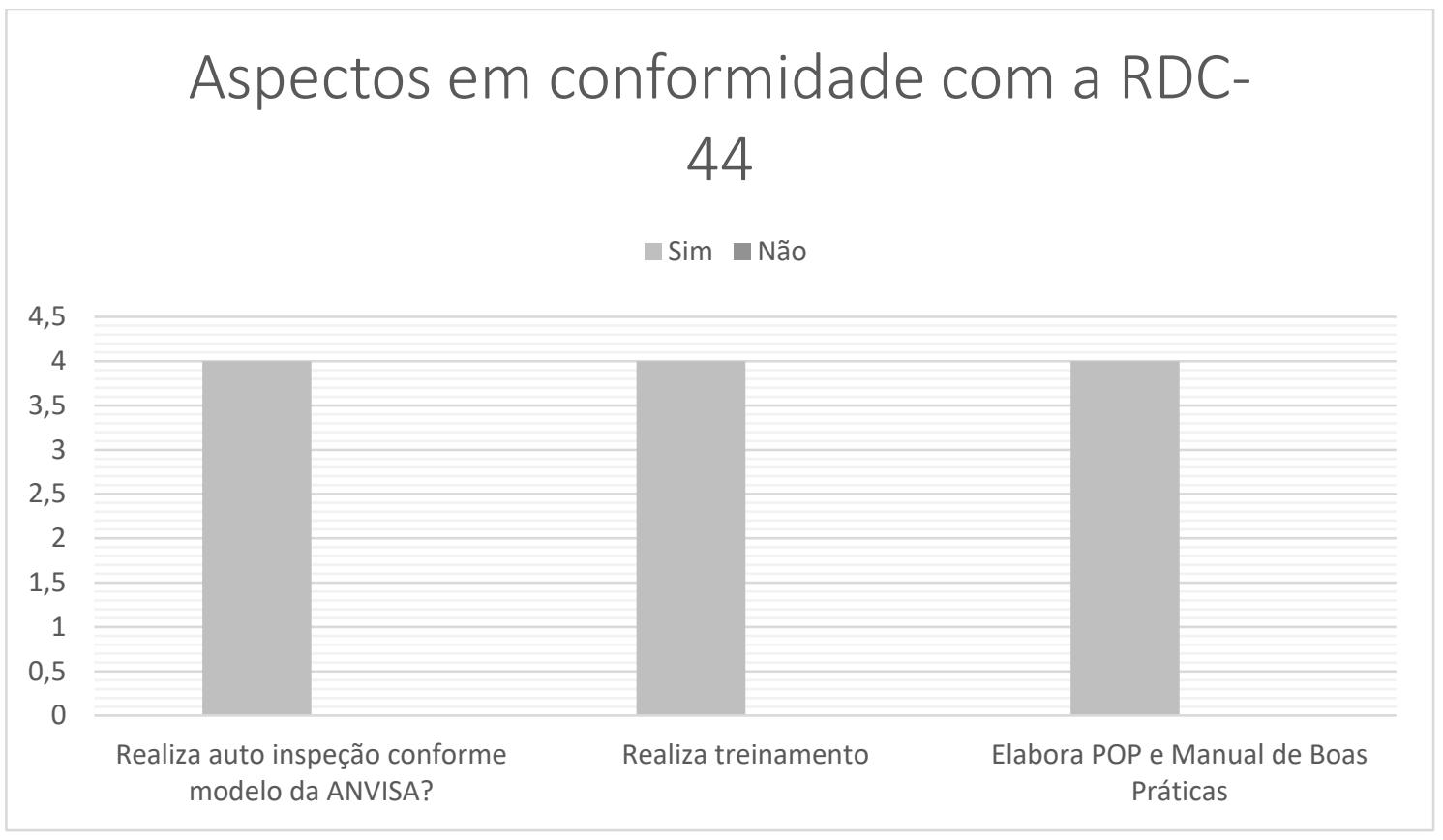

Fonte: Dados da pesquisa, Tremedal-BA, 2016.

Neste sentido, constatamos que as drogarias e farmácias deste município estão de acordo com as Boas Práticas Farmacêuticas estabelecidas para o controle sanitário do funcionamento, da dispensação e da comercialização de produtos e da prestação de serviços regimentados pela RDC-44 a fim de assegurar a manutenção da qualidade e segurança dos produtos disponibilizados e dos serviços prestados em farmácias e de contribuir para a qualidade de vida dos usuários destes serviços.

Os dados colhidos indicaram que 50\% dos farmacêuticos entrevistados não verificam a realização de exames ocupacionais, estando em desacordo com a Resolução RDC nº 67, de 08 de outubro de 2007. Esta RDC institui que a farmácia

deve assegurar a todos os seus trabalhadores a promoção da saúde e prevenção de acidentes, agravos e doenças ocupacionais, priorizando as medidas promocionais e preventivas, em nível coletivo, de acordo com as características do estabelecimento e seus fatores de risco, cumprindo Normas Regulamentares (NR) sobre Segurança e Medicina do Trabalho (ANVISA, 2007, p.1).

Com relação a prestação de atendimento domiciliar $100 \%$ dos entrevistados afirmam não adotar este tipo de prática. $\mathrm{O}$ atendimento domiciliar consiste na atenção farmacêutica que 
Id on Line Revista Multidisciplinar e de Psicologia

Id on Line Multidisciplinary and Psycology Journal

é disponibilizada pela drogaria ou farmácia no domicilio do usuário; a RDC-44 rege no Parágrafo único do Art.68 desta resolução que

A prestação de atenção farmacêutica domiciliar por farmácias e drogarias somente é permitida a estabelecimentos devidamente licenciados e autorizados pelos órgãos sanitários competentes (ANVISA, 2009, p.7)

Embora a Resolução 585 institua que o farmacêutico deva realizar o acompanhamento fármaco terapêutico, a fim de verificar como o paciente está tomando o medicamento, se está utilizando na hora certa a fim de garantir uma assistência de qualidade, sobre este quesito constatou-se que $75 \%$ dos entrevistados afirmaram não realizam este acompanhamento e apenas $25 \%$ a executa, sendo que esta atribuição cabe a todos os farmacêuticos, conforme regulamenta a resolução citada.

Sabendo que o responsável pelo controle da escrituração dos medicamentos e insumos no Sistema Nacional de Gerenciamento de Produtos Controlados- SNGPCé o farmacêutico (responsável técnico cadastrado) e na ausência dele o seu substituto, que deverá ser também cadastrado no sistema de segurança da Anvisa, perguntou-se aos participantes da pesquisa "Se dispensa controlados, é o responsável pelo envio de dados ao SNGPC”, obtivemos que 75\% disseram que sim, e $25 \%$ não (cf. Gráfico 3). Vale salientar que o entrevistado que não executa este relatório é trabalhador da rede pública e o envio destes dados só ocorre em farmácias e drogarias privadas que possuem Cadastro Nacional de Atividade Econômica (CNAE) (cf. Gráfico 3).

\section{GRÁfICO 3-QUANTIDADE DE FARMACÊUTICOS QUE SÃo RESPONSÁVEIS PELO ENVIO DE} DADOS AO SNGPC.

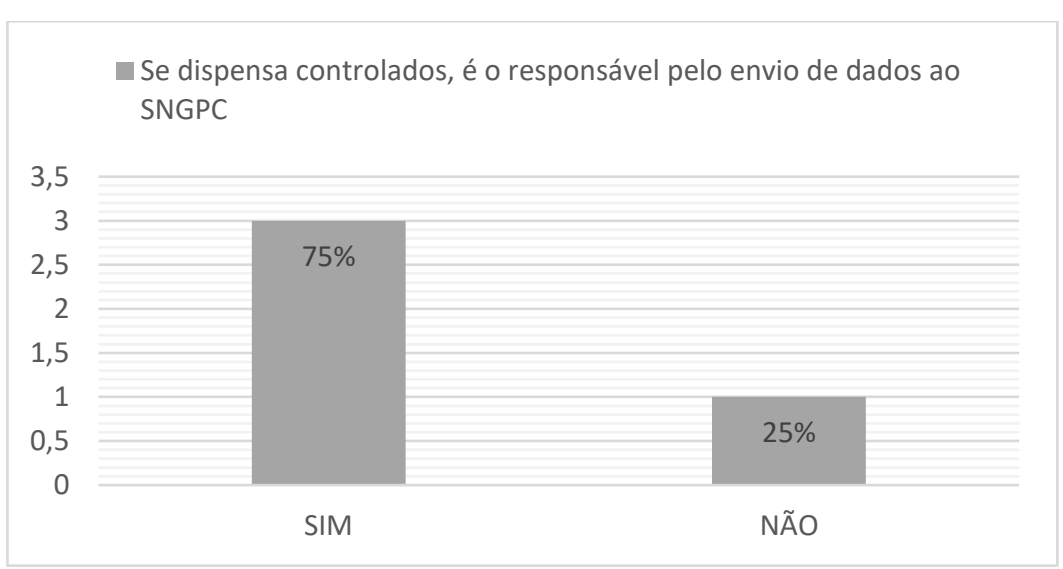

Fonte: Dados da pesquisa, Tremedal-BA, 2016. 
Id on Line Revista Multidisciplinar e de Psicologia

Id on Line Multidisciplinary and Psycology Journal

\section{Considerações Finais}

Sabendo que a Assistência Farmacêutica é o conjunto de ações que visam a promoção, proteção e recuperação da saúde, cujo medicamento é o insumo essencial que deve ser utilizado de maneira racional e tem como escopo contribuir na qualidade de vida da população, integrando ações de reabilitação da saúde, apoiando as ações na promoção do acesso aos medicamentos essenciais e promovendo seu uso racional.O presente estudo estabeleceu como pergunta norteadora: de que forma ocorre a assistência farmacêutica no município de Tremedal - Bahia? E teve como objetivo geral: avaliar como é realizada a assistência farmacêutica no município de Tremedal - BA.

Os dados colhidos apontaram que maior parte dos farmacêuticos da rede privada (75\%) e a menor parte da rede pública (25\%). Visualizamos, dentre os possíveis serviços prestados pelos farmacêuticos do município de Tremedal-BA, que 100\% dos participantes realizam a dispensação de medicamentos controlados, e 75\% deles realizam o recebimento, armazenamento e dispensação de medicamentos; seguidos de $50 \%$ que realiza a aquisição de medicamentos da farmácia e $25 \%$ que realiza, também, a aferição da pressão arterial dos clientes.Sobre a dispensação das medicações, viu-se que $75 \%$ dos entrevistados afirmaram repassar as medicações controladas somente com as receitas e as demais são vendidas conforme a solicitação e apenas $25 \%$ disse realizar a dispensação mediante prescrição médica em casos de internamento e conforme o uso no pronto atendimento, onde se utiliza um caderno de saída para controlar o estoque.

Embora tenha se constatado que $100 \%$ dos entrevistados estão de acordo com o que rege a RDC $\mathrm{N}^{\circ} 44$, no tocante a três aspectos: realização da auto inspeção, treinamento e elaboração POP e Manual de Boas Práticas, compreende-se que o município investigado é carente de Assistência Farmacêutica, a começar pelo número de farmacêuticos na rede pública, que é inferior ao que se recomenda, e que não promovem a devida assistência aos pacientes, como era de se esperar. Enquanto que na rede privada, o objetivo maior é realizar as vendas do medicamento e não prestar a devida atenção farmacêutica que mantenha a qualidade de vida dos cidadãos, em conformidade com as resoluções firmadas pelo Conselho Federal de Farmácia. 
Id on Line Revista Multidisciplinar e de Psicologia

Id on Line Multidisciplinary and Psycology Journal

Espera-se com este trabalho suscitar reflexões sobre a importância da Assistência Farmacêutica para aqualidade de vida da população seja melhorada; cabe, as secretarias de saúde do município refletir mudanças a serem instauradas no SUS e os gestores de ambas redes reverem suas práticas com vistas à execução de progresso no que diz respeito à atenção farmacêutica.

\section{Referências}

ANVISA - Agência Nacional de Vigilância Sanitária. Resolução RDC $n^{\circ}$ 67, de 08 de outubro de 2007. Disponível em:

http://www.vigilanciasanitaria.sc.gov.br/index.php/download/category/122-arquitetura-deprojetos-de-saude?download=1078:resolucao-rdc-n-67-2007-farmacia-de-manipulacaomagistral-ver-rdc-21-2009-e-67-2007 Acesso em 01 de Novembro de 2016.

ANVISA - Agência Nacional de Vigilância Sanitária. Resolução RDC $N^{o} 44$, de 17 de Agosto de 2009. Disponível em: http://cfo.org.br/wp-content/uploads/2010/02/180809_rdc_44.pdf Acesso em 01 de Novembro de 2016.

BASILE, R. P. A importância da assistência farmacêutica,Portal Educação,2008.Disponível em: http://www.portaleducacao.com.br/farmacia/artigos/119/a-importancia-da assistenciafarmaceutica. Acessado em 20 de março de 2016 às $20 \mathrm{~h} 49 \mathrm{~min}$.

BRASIL, MINISTÉRIO DA SAÚDE. Aquisição de Medicamentos para Assistência Farmacêutica no SUS:orientações gerais. Brasília, Ministério da Saúde, 2006.

. Manual do Agente Comunitário de Saúde-2010a. Disponível em: http://www.ebah.com.br/content/ABAAAemIIAK/manual-agente-comunitario-saude. Acessado em 10 de abril de 2016 às $21 \mathrm{~h} 23 \mathrm{~min}$.

. Relação Nacional de Medicamentos Essenciais-RENAME, 2010b.Disponível em: http://bvsms.saude.gov.br/bvs/publicacoes/rename_2010.pdf. Acessado em 23 de abril de 2016 às $21 \mathrm{~h} 50 \mathrm{~min}$.

CFF - Conselho Federal de Farmácia. Resolução $N^{o} 505$ de 23 de Junho de 2009. Disponível em: http://www.cff.org.br/userfiles/file/resolucoes/505.pdf. Acesso em 20 de Novembro de 2016 as $07 \mathrm{~h} 19 \mathrm{~min}$.

.Resolução $N^{o} 585$ de 29 de Agosto de 2013.Disponível em: http://www.cff.org.br/userfiles/file/resolucoes/585.pdf. Acessado em 23 de abril de 2016 às $15 \mathrm{~h} 08 \mathrm{~min}$. 
Id on Line Revista Multidisciplinar e de Psicoloqia

Id on Line Multidisciplinary and Psycology Journal

GIL, A.C. Métodos e Técnicas de Pesquisa Social.6a . Ed. São Paulo: Atlas, 2008.

MATTAR, F. N. Pesquisa de marketing, $3^{\text {a }}$ ed. São Paulo: Atlas, 2001.

OPS - ORGANIZAÇÃO PANAMERICANA DE SAÚDE. Consenso Brasileiro de Atenção Farmacêutica:Proposta. Brasília, Organização Pan-americana de Saúde, 24 p, 2002 b.

PINHEIRO, A.C.M. Gerenciamento de Estoque Farmacêutico. Revista eletrônica de contabilidade, Vol.1, n.3, 2005.

PROFAR - Programa de Suporte ao Cuidado Farmacêutico na Atenção à Saúde. Serviços Farmacêuticos: Contextualização e Arcabouço Conceitual. Conselho Federal de Farmácia, 2014.

VIEIRA, F. S. Assistência Farmacêutica no sistema público de saúde no Brasil, Revista Pan americana de Saúde Pública,Vol.2, n. 27, 2010. Disponível em:

http://www.scielosp.org/pdf/rpsp/v27n2/a10v27n2.pdf. Acessado em 27 de Março de 2016.

\section{Como citar este artigo (Formato ABNT):}

SANTOS, B.O.; BITTENCOURT, F.O. Análise da Qualidade de vida e fatores associados dos Acadêmicos da área de Saúde de uma Faculdade Particular. Id on Line Revista Multidisciplinar e de Psicologia, Janeiro de 2016, vol.10, n.33, p.198-211. ISSN: 1981-1179.

Recebido: 27/10/2016

Aceito: $29 / 11 / 2016$

(*) Anexo Questionário Utilizado na Pesquisa

1 - Você reside no município de Tremedal?

( ) Sim; ( ) Não

2 - Qual local você trabalha?

( ) Rede pública;

( ) Rede privada;

3 - Quais os serviços farmacêuticos você realiza?

( ) Aferição da pressão arterial;

( ) Glicemia capilar;

( ) Administração de injetáveis;

( ) Perfuração de lóbulo auricular;

( ) Aquisição de medicamentos;

( ) Dispensação de medicamentos;

( ) Armazenamento;

( ) Recebimento;

( ) Dispensação de controlados;

( ) Prescrição farmacêutica; 
4 - De que forma é realizada a dispensação das medicações?

( ) o paciente pede e eu entrego a medicação;

( ) só vendo as medicações com receita médica;

( ) repasso as medicações controladas somente com as receitas e as demais, se não forem de uso controlado, vendo conforme a solicitação;

5 - De que forma e por quem é gerenciada a farmácia que você trabalha?

( ) pelo dono da farmácia;

( ) pelo farmacêutico;

( ) por um administrador;

6 - De que forma é realizada a aquisição das medicações?

( ) Mediante sistema;

( ) Bloco de faltas;

( ) Conforme solicitação do paciente;

7 - Para se efetuar as compras das medicações é necessário dar entrada ao processo de licitação?

( ) $\mathrm{Sim}$;

( ) Sim, mas sempre tem medicação a mais na farmácia;

( ) Não;

8 - Realiza a auto inspeção conforme modelo da ANVISA?

( ) Sim; ( ) Não

9 - Realiza treinamento?

( ) Sim; ( ) Não

10 - Verifica se os funcionários realizam os exames ocupacionais?

( ) Sim; ( ) Não

11 - Realiza atendimento domiciliar?

( ) Sim; ( ) Não

12 - Realiza acompanhamento fármaco terapêutico?

( ) Sim; ( ) Não

13 - Elabora POP e Manual de Boas Práticas?

( ) Sim; ( ) Não

14 - Se dispensa controlados, é o responsável pelo envio de dados ao SNGPC?

( ) Sim; ( ) Não

15 - Existe algum check-list utilizado para checar as medicações que entra e sai da farmácia? ( ) Sim; ( ) Não 